\title{
Amizade em mosaico: a correspondência de Oswald a Mário de Andrade
}

\section{Gênese Andrade}

Resumo Neste ensaio, focaliza-se a amizade entre os dois modernistas, a partir da correspondência enviada por Oswald de Andrade a Mário de Andrade de 1919 a 1928. Palavras-chave Oswald de Andrade; Mário de Andrade; correspondência; Modernismo brasileiro.

\footnotetext{
Abstract In this essay one focuses on the friendship between the two modernists and in the correspondence sent by Oswald de Andrade to Mário de Andrade from 1919 to 1928. Keywords Oswald de Andrade; Mário de Andrade; correspondence; Brazilian Modernism.
} 
[...] duas almas, opostas e complementares, do espirito modernista.

[Antonio Arnoni Prado]

Diante dos fragmentos Oswald e Mário de Andrade se conheceram em 1917 e construíram uma amizade que durou até meados de 1929, quando romperam definitivamente. A importância dessas figuras, em sua época e depois, torna impossivel abordar o Modernismo brasileiro sem mencioná-las, e aludir a um implica quase sempre aludir ao outro. Essa relação, que sempre alternou camaradagem e conflitos, convergências e divergências, ficou documentada em textos diversos e também em cartas.

Integram a correspondência passiva de Mário de Andrade, depositada no Instituto de Estudos Brasileiros da Universidade de São Paulo, 27 documentos remetidos por Oswald de Andrade, entre 1919 e 1928, sendo seis cartões-postais e o restante cartas e bilhetes inéditos. ${ }^{1}$ Nesses escritos, permeados pela blague, frases espirituosas, provocações, transparece a admiração por Mário, e Oswald se revela a figura sarcástica, divertida, vaidosa que suas biografias e suas memórias já demonstraram, mas também o camarada e amigo que poucos ousaram reconhecer nele.

Exceto a primeira correspondência, que, pelas circunstâncias em que se insere, inferimos proceder de São Paulo, todas as demais são enviadas por Oswald de outros lugares. $O$ caráter central que a viagem ocupa em sua vida e obra, como já o demonstrou Antonio Candido, ${ }^{2}$ confirma-se em sua epistolografia. No porto,

1 Este material faz parte da série Correspondência, do Arquivo Mário de Andrade, patrimônio do IEB-USP. Os cartōes-postais foram publicados em MORAES, Marcos Antonio de (Org.). Tudo está tão bom, tão gostoso... Postais a Mário de Andrade. São Paulo: Edusp/ Hucitec, 1993. As cartas só foram disponibilizadas para consulta em 1995, conforme determinação expressa de Mário de Andrade de que alguns documentos somente deveriam ser abertos cinquenta anos após sua morte. Algumas cartas são citadas em introduçōes e notas às ediçōes mais recentes de sua epistolografia: MORAES, Marcos Antonio de (Org.). Correspondência Mário de Andrade \& Manuel Bandeira. Săo Paulo: IEB/ Edusp, 2000; AMARAL, Aracy (Org.). Correspondência Mário de Andrade \& Tarsila do Amaral. São Paulo: IEB/ Edusp, 2001; FROTA, Lélia Coelho (Org.). e SANTIAGO, Silviano (Intr. e notas) Carlos \& Mário - Correspondência. Rio de Janeiro: Bem-te-vi Produçōes, 2003.

2 CF. CANDIDO, Antonio. “Oswald viajante”. In: Vários escritos. $3^{a}$ ed. rev. e ampl. São Paulo: Livraria Duas Cidades, 1995, p. 61-6. O crítico afirma: "Viajar para ele é nāo apenas buscar coisas novas, mas purgar as lacunas da sua terra"; e ainda:"a viagem era também um meio de conhecer e sentir o Brasil, sempre presente, transfigurado pela distância" (p. 62).

162 ANDRADE, Gênese. Amizade em mosaico... 
a bordo ou da Europa, dá notícias do que vê e faz, quer saber do que ocorre no Brasil e quer participar, nem que seja à distância, daquilo que acontece em sua ausência. Assim, cartões-postais, cartas e bilhetes dão conta de sua "fome de mundo e de gente, de ideias e acontecimentos", ${ }^{3}$ de seus roteiros, impressões, aventuras, e também tratam dos negócios literários. Oswald pede livros, revistas, informações, e manda notícias dos encontros com artistas, das relações travadas, das possibilidades de intercâmbio, enfim, de sua intensa atividade de divulgação do Modernismo brasileiro, incluída sua própria obra e também a de Mário.

0 estudo deste conjunto epistolar permite delinear a amizade que os uniu. Mas, grosso modo, o que prevalece, durante e após sua leitura, é a frustração decorrente da impossibilidade de completar o mosaico: faltam peças fundamentais. Desconhece-se o paradeiro das cartas de Mário a Oswald, que provavelmente existem, ou existiram, pois aquele não costumava deixar de responder. Em alguns casos, as cartas de Mário a Tarsila constituem respostas a Oswald, preenchem lacunas, mas não as eliminam totalmente. Além disso, fica sempre a dúvida se não houve outras missivas, anteriores, concomitantes ou posteriores às arquivadas, que mudariam o curso da história $\mathrm{e}$ das interpretações. Sem deixar de lamentar os estilhaços perdidos, vamos recompor a relação quase fraterna destes dois bastiōes do Modernismo brasileiro.

\section{Juntando as peças}

Como repórter, vou a uma festa no Conservatório Dramático e Musical. O dr. Sorriso que é o Elói Chaves, Secretário da Justiça, faz ali uma conferência de propaganda dos Aliados. Quem o saúda é um aluno alto, mulato, de dentuça aberta e de óculos. Chama-se Mário de Andrade. Faz um discurso que me parece assombroso. Corro ao palco para arrancar-lhe das mãos o original que publicarei no Jornal do Commercio. Um outro repórter, creio que d'O Estado, atraca-se comigo para obter as laudas. Bato-o e fico com o discurso. Mário, lisonjeado, torna-se meu amigo. ${ }^{4}$

3 Idem. "Digressão sentimental sobre Oswald de Andrade". In: Vários escritos. cit., p. 89.

4 ANDRADE, Oswald de. Um homem sem profissão. Memórias e confissões. Sob as ordens de mamãe. São Paulo: Globo, 2002, p. 160. 
Assim Oswald de Andrade registra, em suas memórias, o início da amizade com Mário de Andrade, que ocorre precisamente no dia 21 de novembro de 1917. A admiração intelectual e a disputa que constituem o marco zero deste relacionamento caracterizarão também seu desenrolar, sua ruptura e o que se sucede a ela. Nessa ocasião, os escritores já se conheciam, pois Oswald havia sido colega de ginásio de Carlos de Moraes Andrade, irmão de Mário, mas não eram próximos. ${ }^{5}$ A primeira correspondência de Oswald que integra o arquivo de Mário é um cartão de luto, papel branco com moldura preta:

Recebi a tua excelente carta. Não me sinto com forças para respondê-la. Estou arrasado, meu ótimo amigo e isso numa idade de poucos entusiasmos. Sinto-me incapaz de reconstruir.

Fica-me, com a saudade imortal de minha esposa, a simpatia caridosa de alguns amigos. E isso me basta. ${ }^{6}$

O cartão, sem data, pode ser situado no tempo a partir do fato ao qual se refere: a morte de sua esposa. Maria de Lourdes Pontes, conhecida como Daisy, Dasy, Deisi ou Miss Cyclone - com quem Oswald se relacionou em 1918 e 1919 -, faleceu a 24 de agosto, aos dezenove anos, pouco depois do casamento, in extremis, realizado no dia 11 de agosto. A história desse relacionamento pode ser acompanhada em O perfeito cozinheiro das almas deste mundo...: Diário coletivo da garçonnière de Oswald de Andrade.7 Aí estão os registros de todos os que passaram por esse pequeno apartamento da rua Líbero Badaró, que curiosamente parece não ter sido frequentado por Mário - ou ele passou por lá sem deixar marcas. ${ }^{8}$

5 Esta informação, com variantes, consta das biografias: FONSECA, Maria Augusta. Oswald de Andrade (78901954): biografia. São Paulo: Secretaria de Estado da Cultura/ Art Editora, 1990, p. 99; BOAVENTURA, Maria Eugenia. O salão e a selva: uma biografia ilustrada de Oswald de Andrade. Sāo Paulo: Ex-Libris/ Campinas: Editora da Unicamp, 1995, p. 75

6 Ao transcrever as cartas de Oswald, optamos pela atualização ortográfica dos vocábulos.

7 Edição fac-similar. São Paulo: Ex-Libris, 1987.

8 Destacamos, entre os frequentadores, Guilherme de Almeida, Ignácio da Costa Ferreira, Léo Vaz, Menotti Del Picchia, Monteiro Lobato, Vicente Rao. Muitos dos pseudônimos com que eram assinadas as mensagens deixadas no diário foram revelados por Oswald em seu livro de memórias, citado, no qual ele retoma com detalhes esse dramático episódio. 
Tudo indica que a amizade entre Mário e Oswald se estreita quando este, encantado com os versos de Pauliceia desvairada, livro então inédito, publica o artigo " $\mathrm{O}$ meu poeta futurista", no Jornal do Commercio, a 27 de maio de $1921 .^{9} \mathrm{~A}$ admiração e a disputa entram em cena novamente. Se o texto lança o poeta, traz problemas para o professor do Conservatório Dramático e Musical: naquele momento, o futurismo não era visto com bons olhos no Brasil, mas como "coisa de doidos" No mesmo jornal, em 6 de junho, Mário responde ao artigo, com um texto em forma de carta, assinado por F. Liszt, negando sua filiação ao "futurismo internacional". Este merecerá uma réplica de Oswald no dia 12 de junho, na qual reafirma sua posição." No "Prefácio interessantíssimo" de Pauliceia desvairada, publicado no ano seguinte, Mário volta ao assunto: "Não sou futurista (de Marinetti). Disse e repito-o. Tenho pontos de contato com o futurismo. Oswald de Andrade, chamando-me de futurista, errou"12

Segundo Mário da Silva Brito, Oswald, com o artigo mencionado, "produz o grande benefício de levar Mário de Andrade a vencer sua timidez e passar a atuar mais atrevidamente no movimento". ${ }^{13}$ Opinião semelhante apresenta Antonio Candido: “é provável que a influência inicial de Oswald (mais ousado, mais viajado, mais aberto), haja sido decisiva para levar Mário, tímido e provinciano, ao mergulho no Modernismo". ${ }^{14}$

É o mesmo Oswald que abre espaço para a publicação, no Jornal do Commercio, em agosto e setembro de 1921, de "Mestres do passado", sete textos em que o "poeta futurista" analisa o Parnasianismo e seus principais representantes. ${ }^{15}$ Nesse mesmo ano, os dois modernistas ainda viajam juntos ao Rio de Janeiro, acompanhados por

\footnotetext{
9 Reproduzido em BRITO, Mário da Silva. História do modernismo brasileiro: antecedentes da Semana de Arte

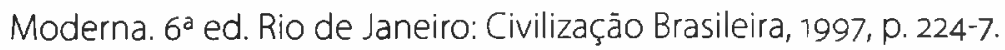

10 "Futurista?!". In: Ibidem, p. 230-5.

11 Ibidem, p. 235-241.

12 ANDRADE, Mário de. "Prefácio interessantíssimo". In: Poesias completas. (Edição crítica de Diléa Zanotto Manfio), São Paulo: Edusp/ Belo Horizonte: Itatiaia, 1987, p. 61.

13 BRITO, Mário da Silva. As metamorfoses de Oswald de Andrade. In: Ângulo e horizonte: de Oswald de Andrade à ficçāo científica. Sāo Paulo: Livraria Martins Editora, 1969, p. 13.

14 CANDIDO, Antonio. Digressão sentimental sobre Oswald de Andrade. Op. cit., p. 77.

15 Cf. BRITO, Mário da Silva. História do modernismo brasileiro: antecedentes da Semana de Arte Moderna. Ed. cit., p. 251. Os artigos também estão aí reproduzidos, p. 251-306.
} 
Armando Pamplona, em busca de outros adeptos para as novas ideias. Em uma crônica no Correio Paulistano, Hélios (pseudônimo de Menotti Del Picchia) noticia esta "bandeira futurista", qualificando Mário como Papa, Oswald como Bispo e Armando como Apóstolo do "novo Credo". 16 Nessa ocasião, Mário lê seus versos na Capital Federal, na casa de Ronald de Carvalho, encantando, entre outros, Manuel Bandeira.

A ideia da Semana de Arte Moderna, aí em gestação, é posta em prática no início de 1922. Novamente os dois estão juntos, participando ativamente do evento no Teatro Municipal de São Paulo, enfrentando as vaias do público e as reações da imprensa, dessa vez em consenso. Em uma possível alusão a Oswald, ao fazer um balanço vinte anos depois, Mário confessa: "O meu mérito de participante é mérito alheio: fui encorajado, fui enceguecido pelo entusiasmo dos outros. Apesar da confiança absolutamente firme que tinha na estética renovadora, mais que confiança, fé verdadeira, eu não teria forças nem físicas nem morais para arrostar aquela tempestade de achincalhes. E se aguentei o tranco, foi porque estava delirando. O entusiasmo dos outros me embebedava, não o meu. [...]"17

Pouco depois da Semana, com a chegada de Tarsila do Amaral da Europa, formam, com esta, Anita Malfatti e Menotti Del Picchia, o Grupo dos Cinco. Em um primeiro momento, unidos por um grande afeto e ideais comuns de produção e divulgação da arte nacional, eles faziam animadas reuniões e passeios pela cidade. Mas o tempo trará competições, rivalidades e intrigas: Tarsila versus Anita, Mário versus Oswald, Menotti contra todos. Este será o tom das relações à medida que a produção aumenta, os nomes se consagram e o movimento modernista se consolida. As menções e as dedicatórias afetuosas nos livros perderão terreno para as farpas, polêmicas, brigas...

Quando Tarsila parte para a Europa em viagem de estudos, no fim de 1922, deixa Mário encantado e Oswald apaixonado. Este não tardará em viajar ao seu encontro, e é neste momento que se intensifica a relação do casal Tarsiwaldo - como o chamava carinhosamente o amigo - com Mário. Do Rio de Janeiro, Oswald escreve a 25 de dezembro:

16 A 'bandeira futurista'. Correio Paulistano, São Paulo, 22.10.1921. In: Ibidem, p. 313-4.

17 ANDRADE, Mário de. O movimento modernista. In: Aspectos da literatura brasileira. $6^{a}$ ed. Belo Horizonte: Itatiaia, 2002, p. 254. 
Você sabia que "quando eu liquidasse os meus negócios..."

Agora, fica sabendo que os liquidei ou, pelo menos, os pus em boa marcha.

E... sigo.

Recomendo-te encarecidamente o número de Graça Aranha. Já sabes, pelo Rubens, que tens a direção artística da "Revista", não?

Adeus, até Mário se Deus quiser.

Vemos que faz questão de comunicar a viagem a Mário o quanto antes, enviando-lhe também seu endereço para correspondência em Paris. A menção à revista Klaxon evoca um desentendimento entre eles em torno da publicação, ao qual voltaremos, e já indica que os "negócios literários" darão o tom da conversa à distância. Refere-se mais exatamente ao número $8 / 9$, que viria a ser o último, dedicado a Graça Aranha e publicado em janeiro de $1923 .{ }^{18}$

Após um postal de Las Palmas, com data de 7 de janeiro de 1923, Oswald envia três cartas e um postal de Portugal. Desde a primeira, de 21 de janeiro, ao seu humor característico, somam-se as piadas sobre os portugueses, inclusive algumas sobre as peculiaridades do acento lusitano:

Entrando em Portugal. Guardas fronteiriços suspeitos de espanholice. E o garbo tradicional da península. Opereta. Opereta a sério. E o raio da delicadeza lusitana, atávica em nós, de se espancarem e dizerem obrigado os primeiros portugueses que vi! Mas o Alvarelhão!!! E o Alvabriga! [...]

O menino do restaurante jura que o que ele fala é português. Na gare reduzida, ainda ocre jaune d'Espagne, as primeiras cachopas! A saúde. $O$ vinho. $O$ rabo entre as pernas. A saudade.

Portugal!

Encontrei um sujeito robustíssimo brigando com os guardas da fronteira por querer pagar direitos. Duelo quase grosseiro de delicadezas. A raça!

Poor Brasil!

18 Klaxon: mensário de Arte Moderna (São Paulo, 1922 - 1923). Edição fac-similar. São Paulo: Martins/ Secretaria de Estado de Cultura, Esportes e Turismo/ Conselho Estadual de Cultura, 1972. 
Provavelmente, confrontar a ex-Metrópole com o Brasil constatando as diferenças inspirará a defesa do elemento nacional no Manifesto da Poesia Pau Brasil, no ano seguinte. Como afirma Candido, a viagem constitui para Oswald "translação mágica de um ponto a outro, cada partida suscitando a revelação de chegadas que são descobertas". ${ }^{19}$ Após uma semana, o viajante manda uma carta sobre os intercâmbios literários realizados e pede a colaboração de Mário para dar continuidade a eles:

Em Lisboa ainda e sempre.

29-1-23

Mário

A geração surpreendente - Contemporânea - à nossa disposição. Manda-lhe Klaxon. É urgente, imprescindível, remete de suite para o meu endereço em França - Comptoir de Commission Americana - 25, Rue Louis le Grand, 25 - diversos exemplares de Pauliceia, o Messidor do Guy, se possível e 3 coleções ou 4 ou 5 de Klaxon.

Dou a V. essa amável incumbência por ser V. o mais bonito da geração (Estamos em Portugal, terrinha da piada). [...]

Portugal Contemporânea é Lindo, sem sombra de blague. Que geração! Parece a nossa! $[\ldots]$

A comparação entre o Modernismo português e o brasileiro é bastante irônica. A revista Contemporânea, na qual colaboraram Fernando Pessoa e outros, circulou de 1922 a 1926. Não sabemos com quem Oswald esteve em contato, já que ele não faz referências específicas. Há aí também duas provocaçōes a Mário: quanto à sua aparência, comentário maldoso, e quanto às reuniões realizadas na rua Lopes

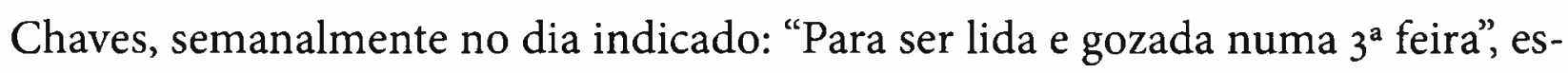
crito na diagonal, no canto superior esquerdo. O próprio anfitrião esclarece como eram esses encontros: "Havia a reunião das terças, à noite, na rua Lopes Chaves. Primeira em data, essa reunião semanal continha exclusivamente artistas e precedeu mesmo a Semana de Arte Moderna. Sob o ponto de vista intelectual foi o mais útil dos salões, se é que se podia chamar salão àquilo". ${ }^{\circ}$

19 CANDIDO, Antonio. Oswald viajante. Op. cit., p. 63.

20 ANDRADE, Mário de. O movimento modernista. Op. cit., p. 261. 
De Paris, Oswald manda sete cartas e um bilhete em 1923, solicitando em todos o envio de publicações, contando sobre as rodas artísticas que frequenta, fazendo provocações e pedindo notícias. Na carta remetida a 25 de fevereiro, informa: "Romains $\mathrm{o} 1^{\circ}$ amigo conquistado. Primeiros contatos efusivos com os outros. Gide na Itália", e diz mandar-lhe um autógrafo de Romains, ao qual se seguirão outros, como o de Cocteau, anunciado no bilhete de 9 de março. A correspondência datada de 4 de março praticamente intima o amigo a cumprir suas solicitações, inclusive com prazos estabelecidos, e traz muitas farpas, retomando também a menção irônica ao salão da rua Lopes Chaves:

Esta carta exige resposta urgente. Les affaires sont les affaires, já dizia aquela besta do Mirbeau. Não tenho o endereço do Serge e por isso recorro a ti. Preciso com certa urgência da tradução francesa d'Os Condenados. Já terá o Serge terminado o trabalho que começou?

Se o tiver feito, peço ainda a ti, favor de amigo, ora! pelo amor de Deus! por quem é! que a remetas a mim, sem perda de tempo, registada para "Comptoir de Commission Americana, 25, Rue Louis le Grand".

A tradução ou qualquer notícia a respeito espero-a dentro de 50 dias - Hoje são 4 de Março, deve estar aqui a 24 de Abril, no máximo. Certo?

Tenho feito o possível por vós. Deixei na mesa de trabalho de Jules Romains o meu volume de Pauliceia. Insistência dele. Conhece o espanhol. Quer decifrar. Pior para ti! Assistir no "Vieux Colombier" La nuit des rois de Shakespeare é melhor que filar aqueles sábios biscoitos domésticos das tuas intelectuais terças-feiras. Juro que é.

Manda também, sem falta, coleções de Klaxon e números da nova fase da Revista do Brasil. Peço mesmo que fales com Paulo Prado ou Lobato. Estou representando aqui uma revista que não possuo, que nem sei como é. Falo dela a todo mundo e quando me pedem para vê-la, o recurso cínico é atribuir à fome intelectual das nossas populações as edições esgotadíssimas dessa nova bíblia mensal.

$[\ldots]$

Seguem-se críticas cortantes ao ambiente artístico, elogios aos literatos já citados e alguns versos com irônica instrução: "leia-se com entonação". além da repetida insistência nos pedidos. Retomando o início da amizade, acrescenta ainda 
uma frase emblemática da relação que mantinham, do desejo de dar notícias e também de recebê-las: "Escreve cartas longas, informativas, minuciosas. E nunca fiques 'O homem que acreditava no futurismo"'

Uma carta de 7 de março, depois dos comentários sobre as rodas literárias, informa: "Estou amigado"; é a primeira referência a sua relação amorosa na correspondência. Em outra, de 18 de abril, aparece a primeira menção de que recebeu carta de Mário:

Recebi tua carta ansiosa. Que se passa? Todos os dias passam-se coisas novas. Estou já há bastante tempo na intimidade de Picasso, Cocteau, Romains e Larbaud. Há dificuldades em encontrar os outros. Max Jacob vive num convento do Loire. Cendrars é metteur-en-scène dum cinema. Ninguém sabe dele. Descansa, porém. A todos direi da tua admiração mineira.

[...] Brecheret, você, Menotti e a corja serão lançados por mim em próxima conferência. Grande agitação nos arraiais da América Latina em Paris e nas trincheiras do ronsardismo triunfante. Aí, eu tinha vergonha de confessar que era árcade, parente longe de todos os Alvarengas da nossa poesia. Aqui, porém, isso é indiscutivel figurino. Fizeste bem em confessar no prefácio de Pauliceia que eras passadista. Vou vilmente me aproveitar disso na minha conferência. Peço-te Klaxon, a Revista do Brasil e a fidelidade. [...]

Refere-se, sem muitos detalhes e com muito humor, à conferência que fará em breve. Ao dar notícias dos brasileiros que estão em Paris, diz de Tarsila: "íntima de Lhote e Juan Gris, a quem me apresentará". Essa carta é mencionada em correspondência de Mário a Tarsila, de 20 de maio:

Contou-me o Oswald que és agora amiga de Lhote e Juan Gris... Bravo! Mas não te esqueças que ser modernista não implica o esquecimento dos amigos! Escreve-me alguma coisa. Conta-me de ti. Teus projetos, anseios, vitórias. Sabes perfeitamente quanto me interessa qualquer coisa que te diga respeito. $[\ldots]^{21}$

21 AMARAL, Aracy (Org.). Correspondência Mário de Andrade \& Tarsila do Amaral. Ed. cit., p. 64. 
Vemos que a ânsia por notícias é mútua. Como um verdadeiro embaixador do Modernismo, Oswald faz contatos incansavelmente. Em uma carta sem data, que supomos suceder a anterior, fala do encontro com Cendrars, que lhe manda um autógrafo, e de forma mais objetiva sobre a conferência que fará na Sorbonne, no dia 11 de maio:

Jantarei Lundi com Cendrars dans la Maison.

Camaradas intuitivos.

Referi-lhe a chapelle-tu, luis aranha. Não se comoveu. Perdeu um braço na guerra, o direito. Perdeu os dentes na paz da vida.

Irá ao brasil, cinematograficamente. Manda-te um autógrafo - A mes amis du Brésil. La Tour de Babel - Blaise Cendrars. ${ }^{22}[\ldots]$

Farei, a 11 próximo, uma conferência na Sorbonne. Reconciliarei Cendrars com Pio 11. Onze mil virgens. [...]

Uma carta de 9 de maio, datada erroneamente como de 9 de abril, ${ }^{23}$ assinada como Barnabooth, é escrita entre os preparativos para a conferência e a redação do segundo volume da Trilogia do Exílio, $A$ estrela de absinto, do qual já havia publicado trechos em Klaxon, mas que só será editado em 1927. Em meio a muitos trocadilhos, Oswald provoca Milliet, menciona com ironia a divulgação da obra do amigo na Europa e ataca a cidade que vaiou a Semana de 22:

\section{$[\ldots]$}

Antevéspera da Sorbonne - Ando subornado pela emoção. O Serge em vez de trabalhar pela pátria - Pátria, lá o Tejo em ti! faz trocadilhos latejantes. [...]

Este desenho está reproduzido em EULÁLIO, Alexandre. A aventura brasileira de Blaise Cendrars. $2^{\mathrm{a}}$ ed. rev. e ampl. por Carlos Augusto Calil, com inéditos de Blaise Cendrars. São Paulo: Edusp/Imprensa Oficial/ FAPESP, 2001, p. 386.

23 Considerando que Oswald fala da conferência na carta de 18 de abril, concluímos que esta se realizou no dia 11 do mês seguinte; isso se confirma com o fato de que conta sua repercussão em carta de 15 de maio. Não nos parece provável que a data da carta de 18 de abril esteja errada, nem que a conferência tenha sido em abril, pois ele não demoraria mais de um mês para mandar essas notícias. Sendo assim, a data "9-4-23" da carta que informa "antevéspera da Sorbonne" só pode ser um equívoco. 
Espalhamos por aqui que você é um bicho. Aliás sem convicção nenhuma. Você é necessário ao momento brasileiro em Paris como o marechal Figa foi útil à política do Pinheiro Machado. [...]

Comédie no sábado e também o New York Herald falarão bem de nós. Já está tudo combinado. Mesmo que eu diga asneiras. É o grande jornalista Serge Milliet quem assume responsabilidades. Você, nos seus artigos, poderá provar que São Paulo (a Pauliceia, não o livro, a cidade do livro) é uma besta. Vaiou-me na Semana de Arte Moderna. Quando esta aí aportar Paris me terá aplaudido na Sorbonne. Não foi à toa que o Miguel Meira me beijou a mão num meeting do Abaixo-Piques, lá vai anos.

O Serge reclama que está na hora... É hora! Ó Boaventura dos arrepios cardíacos que eu senti no meu exílio. Trilogia! Taratachismo!

$[\ldots]$

Publicada na Revue de l'Amérique Latine, em julho, e em português na Revista do Brasil, em dezembro, ${ }^{24}$ a conferência, de caráter panorâmico, abrange a literatura, as artes plásticas, a música e as ideias no Brasil. Aracy Amaral chama a atenção para o fato de que aí não transparece o tom polêmico e sua fala não é nada revolucionária quanto aos propósitos dos modernistas. ${ }^{25}$ Surpreende a menção a Mário, mas não a Pauliceia desvairada; a Menotti e seu livro O homem e a morte, com os quais o conferencista polemizara, como veremos a seguir, associados aos nomes da vanguarda internacional com que passara recentemente a se relacionar. Oswald escreve, a 15 de maio, para contar sua repercussão:

Até eu, pelo binoculinho às avessas da modernidade ocidental (R. Lopes Chaves - São Paulo - Brésil - Amerique du Sud - 15 jours de mal de mer) fui enxergado romancista de $2^{\text {a }}$ classe. Natural, lógico, justo, que Menotti se despreocupe de vocês que viram nele homem de letras de $3^{\mathrm{a}}$.

\footnotetext{
24 Revue de l'Amérique Latine. (Paris), ano 2, n. 5, p. 197-207, 1.7.1923; Revista do Brasil. (São Paulo/ Rio de Janeiro), ano VIII, vol. XXIV, n. 96, p. 383-9, dez. 1923. Reproduzida em BATISTA, Marta Rossetti et alii (Org.) Brasil, $1^{\circ}$ tempo modernista - 1917-29: documentação. São Paulo: IEB-USP, 1972, p. 208-16.

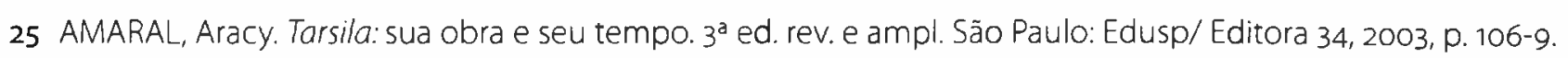

172. ANDRADE, Gênese. Amizade em mosaico... 
A minha conferência causou boa impressão. Na sala, Jules Romains, Paul Morand, Juan Gris, Nicolas Baudoin etc., embaixadores, condessas, artistas etc. Coitado de mim se não visse no Homem e a morte nossa melhor obra moderna! Outras vítimas da maçonariazinha da rua Lopes Chaves satisfazem perfeitamente as exigências da "modernidade de Paris" - Graça, Ronald, Tarsila. Ao contrário, João Epstein é considerado um traste. [...]

Apesar de ter podido pagar a vocês na moeda com que vocês negociaram a minha obra, disse agradáveis verdades de todo o grupo na Sorbonne. "A vingança do justo consiste em perdoar" G. Junqueira - ob. crít. ${ }^{26}$

Aí aparece também a primeira referência de Oswald às intrigas de São Paulo. Trata-se do desentendimento ocorrido em 1922, na redação de Klaxon, pouco antes de sua partida. Segundo depoimento de Rubens Borba de Moraes a Aracy Amaral, a raiz da discussão esteve no fato de que o grupo da revista havia escrito um artigo bastante negativo sobre O homem e a morte, de Menotti Del Picchia. Mário discordou disso e, defendendo Menotti, propôs-se a escrever um texto que substituiria o anterior. Seu artigo saiu excessivamente elogioso, e só depois de muita discussão ele autorizou que os companheiros o alterassem para publicação. ${ }^{27}$ É previsível que Oswald tenha se enfurecido não só com a atitude de Mário de querer que sua opinião prevalecesse, mas também com o elogio exagerado, que praticamente elevava o livro de Menotti ao melhor do ano, em detrimento de Os condenados, também de 1922.

É curioso que as cartas anteriores não tenham vestígios dessa briga; ao contrário, o tom do texto de Oswald é sempre divertido e amável, com envio de autógrafos, para agradar a Mário de Andrade ou para causar-lhe inveja. Dessa vez, porém, lava a alma, concluindo em estilo esnobe: "A vingança do justo consiste em perdoar" Para ele, não poderia ter havido melhor ajuste de contas.

Na primeira correspondência de Tarsila a Mário depois da partida, datada de 23 de maio, tendo já recebido três cartas da rua Lopes Chaves, ela se refere

26 Mário comenta o conteúdo dessa carta em correspondência a Manuel Bandeira datada de 22 de maio. Cf. Correspondencia Mário de Andrade \& Manuel Bandeira. Ed. cit., p. 92.

27 Nota 13. In: Correspondência Mário de Andrade \& Tarsila do Amaral. Ed. cit., p. 73. 
indiretamente ao episódio para justificar a demora em responder: "Escrevi ao Menotti uma carta terrível contra você. O Osvaldo logo que chegou fez tantas intrigas entre nós (a respeito da modernidade ocidental) que resolvi cortar relações com você. Mas vieram as suas cartas, as suas irresistíveis cartas - knock-out!" 28

Supõe-se que Oswald lia as cartas que Tarsila enviava a Mário, interferia em seu conteúdo e provavelmente exercia influência sobre ela quanto à interpretação dos fatos que os envolviam. Em contrapartida, as cartas de Mário a Tarsila são consideradas também dirigidas a ele como um "terceiro interlocutor", nas palavras de Aracy Amaral, ${ }^{29}$ ou até mesmo "o verdadeiro interlocutor", "o parceiro oculto", segundo Sergio Miceli. ${ }^{30}$ Isso se comprova na resposta de Mário a Tarsila, datada de 16 de junho, na qual faz questão de apresentar ao casal Tarsiwaldo sua versão do ocorrido:

Foi bom deixar que passassem dois dias depois do recebimento da tua carta, para te escrever. Já agora passou a primeira forte irritação que me causou o procedimento do Oswaldo. [...] Não sei, nem quero imaginar o que te disse Oswaldo a meu respeito. Sei que não mentiria. Não é dele mentir. Mas sei também que exagerou. E muito. [...] Mas queres que te conte do Oswaldo? Mostra esta carta a ele. Dirá se é verdade o que aqui está. ${ }^{31}$

Segundo Mário de Andrade, após o episódio na redação de Klaxon acima citado, Oswald vai ao escritório um dia e o ataca em sua ausência. Quando Mário chega e pede explicações, o autor de Os condenados recua, mas o magoa com outras acusações, e ainda mente atribuindo palavras a Menotti que este desmentirá. Mário diz também que Oswald tentara desacreditá-lo no Rio e agora em Paris. Nesse confronto por escrito, é incisivo: "Esta carta é para que ele a leia". Acusa-o ainda de não praticar uma crítica isenta, mas a mesma acusação deve ser devolvida a ele: sua defesa de Menotti era totalmente influenciada pela amizade. Tanto

\footnotetext{
28 Ibidem, p. 68. Mário sempre escreveu o nome do amigo abrasileirando-o e Tarsila às vezes faz o mesmo.

29 De Mário para Tarsila e de Tarsila para Mário. In: Ibidem, p. 20.

30 MICELI, Sergio. Nacional estrangeiro: história social e cultural do modernismo artístico em São Paulo. São Paulo: Companhia das Letras, 2003, p. 115.

31 Correspondência Mário de Andrade \& Tarsila do Amaral. Ed. cit., p. 72.
}

174 - ANDRADE, Gênese. Amizade em mosaico... 
a crítica da época como a posterior não hesitam em reconhecer o pouco talento do autor de $O$ homem e a morte, em especial o menor valor dessa obra comparativamente a Os condenados.

Tarsila responde a Mário a 22 de julho, tentando desfazer o mal-entendido: "Não pensei que você tomasse a sério a minha brincadeira. O Osvaldo e o Serge que aqui estavam no dia em que te escrevi leram a carta. Perguntei-lhes com que olhos você a leria. Concordaram comigo que o knock-out desmanchava intrigas e consequências". ${ }^{32}$ A correspondência que Mário envia a Tarsila a 15 de novembro indica terem se dissipado as mágoas. Dirige-se também a Oswald e Sérgio Milliet para chamar sua atenção para o elemento nacional. Trata-se da exaustivamente citada carta em que reivindica que eles não se esqueçam da arte nacional e se voltem para o autóctone, na qual também anuncia: "Criei o matavirgismo. Sou matavirgista. Disso é que o mundo, a arte, o Brasil e minha queridíssima Tarsila precisam". ${ }^{33}$

Em 1924, Mário, Oswald, Tarsila, dona Olívia Penteado e outros constituem a chamada caravana modernista que acompanha Blaise Cendrars ao Rio de Janeiro durante o Carnaval e às cidades históricas de Minas Gerais durante a Semana Santa. Dessas viagens, resultam o Manifesto da Poesia Pau Brasil, que Oswald publica no mesmo ano no Correio da Manhã, do Rio de Janeiro, e seus desdobramentos.

- Manifesto provoca inúmeras críticas, as mais acirradas provenientes do grupo do Rio de Janeiro: Graça Aranha, Ronald de Carvalho, Renato Almeida. O primeiro faz uma conferência na qual rompe com a Academia Brasileira de Letras, $\mathrm{e}$ ataca Oswald. Este, com apreciação totalmente oposta à que deixara transparecer na conferência na Sorbonne, revida de forma demolidora no artigo "Modernismo atrasado", publicado em $A$ Manhã, de 25 de junho. ${ }^{34}$ Mário lidera a caravana que viaja ao Rio para assistir à conferência, e, às vésperas da partida, Oswald dedica-lhe Memórias sentimentais de João Miramar, recém-publicado, registrando o episódio: “À bancada paulista/ que parte para o Rio afim/ de decidir o 'caso' da/ modernia na acade-/midade/ no seu longo e oculudo/ leader Mário de Andrade/ 
o/ Oswald" ${ }^{35}$ Mas, em carta a Manuel Bandeira, datada de 10 de outubro, Mário afirma condenar a atitude de Graça Aranha. ${ }^{36}$

Nesse ano, o autor de Pauliceia desvairada publica o artigo "Osvaldo de Andrade", na Revista do Brasil, ${ }^{37}$ no qual discorre sobre Miramar - "O livro saiu a mais alegre das destruições" - e sobre a personalidade do amigo, provavelmente influenciado pelas últimas polêmicas: "O mais curioso talvez dos modernistas brasileiros. 'É um blagueur!' dizem. [...] Uma das faculdades que mais admiro em Osvaldo é esse poder certeiro de interessar e divertir. [...] Há muito tempo já que vivo a pensar secretamente ser Osvaldo o melhor espectador de si mesmo. [...]"

No arquivo de Mário, constam apenas duas cartas enviadas por Oswald em 1924: uma quando estava a bordo e outra postada na Suíça. A primeira, em papel timbrado da Compagnie de Navigation Sud Atlantique, presume-se que seja de 15 de novembro, data cívica mencionada. Aí dá conta do que o cerca, com muito humor e frases de efeito:

Illmo. Sr.

Mário de Andrade. Ariel.

Tem esta por obrigação e escopo comunicar-lhe que abandonei a literatura.

Os queijos de bordo não prestam. Em compensação, há o Palma. Gigolô. Cheio de gravatas. Los Angeles nascido em Los Andes. Pergunte à Magdalena. Está na cabina n. 20. Tem fonola, xales. Argentinos passam como piolhos. Oh! Os joelhos de Mistrress Barbara Bind! Sexualidade exacerbada pela maresia.

Todo mundo está notando este namoro. Também é demais. Vá comprometer a avó! Perdão, não chegamos ainda a águas portuguesas.

Ontem Magdalena, entre dois Abdullas (cigarro), leu Ariel. "O caso Magda”. No bar. Comovente. Acha que tem algo de leite de peito o sorriso dele. Sézamo. Cotadote o Sr. Magdario de Andrade. Veja como não tenho ciúmes. Sabes o que é o mar - um melado azul.

35 Este exemplar, como os demais dedicados a Mário, integra o acervo da biblioteca de Mário de Andrade, no IEB-USP.

36 Correspondência Mário de Andrade \& Manuel Bandeira. Ed. cit., p. 135

37 Revista do Brasil. (São Paulo), ano IX, vol. XXVI, n. 105, p. 26-33, set. 1924. Reproduzido em Brasil, 10 tempo modernista - 1917-29: documentaçăo. Ed. cit., p. 219-25.

176. ANDRADE, Gênese. Amizade em mosaico... 
Descobri minha vocação: brasseur d'affaires. Finalidade - uma brasserie qualquer. Comunico-lhes outrossim que estou viajando re mi fa sol neste coador!

Viva o dia 15 de Novembro!!

$[\ldots]$

Refere-se ao artigo de Mário, "O caso Magda Tagliaferro" publicado em Ariel, Revista de Cultura Musical, número 12, de setembro de $1924,{ }^{38}$ em que o crítico discorre sobre uma série de concertos da pianista em São Paulo em 1923 e 1924, refletindo sobre a interpretação da obra de arte musical e seus desdobramentos. Apesar da ironia, Oswald parece alegrar-se em comunicar ao amigo a circulação de suas ideias. Em $1^{0}$ de dezembro de 1924, é a vez de Mário enviar uma carta a Tarsila com provocações a ele como até então não havia ocorrido:

Osvaldo, apesar de todo o cabotinismo dele (quero-lhe bem apesar disso) é fraquinho agente de ligação. A gordura é má condutora, dizem os tratados de física. Era. Hoje está em Paris esse felizardo das dúzias que eu invejo quanto se pode invejar neste mundo. Que faz ele? Mostrou-te o Serafim Ponte Grande? Ficou (o Osvaldo) meio corcundo comigo porque eu disse que não gostei. Mas se ele conhecesse os meus trabalhos atuais, faria as pazes comigo. Estou inteiramente pau-brasil e faço uma propaganda danada do paubrasilismo. [...]

[...] Os Prudente de Morais, neto e o Sérgio Buarque de Hollanda mandaram-me pedir que dissesse ao Osvaldo pra lhes mandar o João Miramar que queriam dar notícia na Estética [...]. Vou por minha conta lhes mandar o livro. O Osvaldo se não gostar que tire as calças e pise em cima. Acho idiota esta briguinha de comadres. Mas como vou assumir a responsabilidade do caso, pede ao Osvaldo que não vá me atrapalhar a política. ${ }^{39}$

Além de aludir a um desentendimento entre eles, Mário menciona a briga com o grupo do Rio, que citamos antes. Apesar disso, encarrega-se da divulgação de Miramar pelo Brasil, assim como Oswald se encarregara da de Pauliceia em Paris

38 É com base na mençāo à revista, cujo título é associado ao nome de Mário, ao artigo citado explicitamente aí publicado e à data cívica mencionada que atribuímos tal data à carta. 39 Correspondência Mário de Andrade \& Tarsila do Amaral. Ed. cit., p. 86-90. 
no ano anterior. A carta é praticamente toda para falar de Oswald, e apenas nas linhas finais se ocupa de pedir notícias de Tarsila.

Entre rompimentos, provocações e reconciliações, Mário dedica $A$ escrava que não é Isaura, publicado em 1925, a Oswald. No fim de 1924 ou início de $1925,{ }^{40}$ este lhe manda uma carta sob o impacto do conhecimento da dedicatória, na qual parodia seu estilo:

\section{Mestre Mário}

$O$ intrigante do Yan me mostrou pra mim uma carta de você que diz assim que você não imita eu. É verdade. Você é a prática culta da língua. Eu é a prática inculta. Pobrezinho que nem MININO DEUS.

Sabe. Me deu pra mim uma comoção de você ofrecer pra mim o seu livro da tal escrava que não se chama Inzaura. Eu prifiria uma iscrava chamada...

Malicioso! Tá rindo! Feio!

Em todo caso fico muito agradecido e não miricia tamanha honra. Sei que você agora deu pra jogador e corrupiê no Automóveis Club. Bem bão! Tá pagando a má língua.

Té logo

Osvardo

Cidade-Luz - domingo despois do baile

É significativo que Mário dedique a Oswald este texto de teoria ou estética da poesia moderna, que tem como subtítulo "Discurso sobre algumas tendências da poesia modernista". Não surpreende, porém, que, quase simultaneamente a essa troca de amabilidades, conclua uma carta a Tarsila, de 7 de janeiro de 1925, com a seguinte frase: "O Osvaldo, já se sabe, sempre me enquisilando".41 Estaria referindo-se à correspondência anterior?

40 Em carta a Bandeira, de outubro de 1924 (Correspondencia Mário de Andrade \& Manuel Bandeira. Op. cit., p. 140), Mário já lhe conta que dedicará o livro a Oswald. O exemplar que Mário Ihe deu tem a dedicatória manuscrita datada de janeiro de 1925 e pertence à coleção de Tarsila (Cf. AMARAL, Aracy A. Tarsila: sua obra e seu tempo. Ed. cit., p. 191). Sendo assim, sua manifestaçāo tanto pode ser ao inteirar-se do fato antes da publicaçāo como ao receber o livro.

41 Correspondência Mário de Andrade \& Tarsila do Amaral. Ed. cit., p. 92. 
Este é o ano em que Oswald edita em Paris o livro Pau Brasil, com ilustrações de Tarsila. No exemplar com que presenteia Mário, põe a seguinte dedicatória: "Ao autor/ de/ Pau... licéa Brasil/ admirado/ o/ Oswald/ 1925" Mário, por sua vez, escreve um artigo sobre este livro, publicado postumamente. ${ }^{42}$ Critica o efeito pelo efeito, a chave de ouro, a incerteza rítmica, mas também faz elogios: "Com esses defeitos qualidades e fartura excepcional de lirismo sério ou cômico acho Pau Brasil a obra mais completa de O. de A.". Este ensaio, juntamente com o anterior, pode ser considerado como a contrapartida de "O meu poeta futurista" - textos em que transparecem a admiração mútua e argutas análises das obras literárias. Encerrando o ano de 1925, Mário envia ao casal o "Poema Tarsiwaldo":

Pegue-se 3 litros do visgo da amizade

Ajunte-se 3 quilos de açúcar cristalizado da admiração

Perfume-se com 5 tragos da pinga do entusiasmo

Mexa-se até ficar melado bem pegajento

E se engula tudo duma vez

$[\ldots]^{43}$

A caminho da Grécia e do Oriente, viagem que o casal realiza no início de 1926, Oswald, a bordo do Lotus, informa em uma breve carta de 14 de janeiro:

Meu querido Mário

Um abraço de Parthenopéia te levará a minha saudade literária. Daqui pra Grécia, Jerusalém, Egito.

Como os velhos roteiros envelhecem!

Oswald Lamartine de Souza Andrade

42 ANDRADE, Mário de. Oswald de Andrade, Pau Brasil. Sans Pareil, Paris, 1925. Reproduzido em Brasil, 10 tempo modernista - 1917-29: documentação. Ed. cit., p. 225-32. Oswald tomou conhecimento desse texto, escrito para ser publicado no número 4 da revista Estética, que não chegou a circular. Cf. Correspondência Mário de Andrade \& Manuel Bandeira. Ed. cit., p. 355.

43 Reproduzido em Correspondência Mário de Andrade \& Tarsila do Amaral. Ed. cit., p. 47. 
Um postal da Grécia e uma carta de Nazaré registram, com muito humor, impressões da viagem. De volta a Paris, onde acompanha Tarsila nos preparativos para sua primeira exposição individual na Cidade-Luz, a histórica mostra na Galerie Percier, manda notícias ao amigo. Na carta de 1 de março, acusa recebimento de Losango cáqui - o qual traz a seguinte dedicatória: "Pro Oswaldo de Andrade/ com o coração do/ Mário/ São Paulo/ 22/1/26"44 - e fala longamente do processo de criação de Serafim Ponte Grande, ${ }^{45}$ que tem episódios inspirados no périplo pelo Oriente, concluindo:

\section{$[\ldots]$}

Como vês, Serafim me preocupa como um filho que nāo quer sair.

Agora coisas sérias.

Recebemos Losango, eu e Tarsila.

Bom, muito bom, ótimo.

Isso é poesia. Vale a pena de ser brasileiro.

Brigaste com Menotti, era fatal. Agradeço-te muito a delicadeza da comunicação.

Caminhos tão diferentes não podiam desembocar na mesma estrada.

E Cendrars? E Paulo, Couto, Sergio, Tácito, Guy, Alcântara, Prudente, Manuel, Yan, Aranha, Rubem.

Manda-me notícias, recortes e números de Terra Roxa. Sobretudo, responde a esta carta.

Tarsila recomenda-se.

A exposição só em Abril.

Oswald, que durante o ano de 1925 polemizara com Menotti em virtude das críticas a Pau Brasil, publicadas no Correio Paulistano, não se surpreende com o fato de que agora seja Mário quem rompa com ele devido à crítica a Losango cáqui na revista Terra Roxa e outras terras, número 2, de 3 de fevereiro, a qual teve réplica dedicatória.

45 Este livro, sobre o qual há comentários na correspondência desde 1924, só será publicado em 1933. 
do autor estampada na mesma página ${ }^{46} \mathrm{Em}$ provável resposta à carta anterior, Mário se dirige a "Tarsivaldo" a 21 de abril, sem perder a oportunidade de alfinetar o amigo:

[...] Eu cismo e ao meu pensamento vem de leve pousar como uma andorinha a recordação de Tarsivaldo. Oh doces lembranças da amizade! Oh recordar assim numa hora assim esses camaradões dá um gosto sossegado e rindo no coração da gente, como que vocês vão, hein? Imagino deste jeito: Osvaldo todo afobado andando léguas arranjando as coisas pra exposição e Tarsila meia com medinho trabalhando ainda algum quadro de última hora. [...] Pois esta é pra desejar felicidades pra Tarsila, não, pra Tarsivaldo porque afinal das contas sei bem que tudo que for felicidade pra um é pro outro. [...] Esta carta é pro Osvaldo aprender como é que se escreve carta, vocês ficaram sabendo do mais importante e me perceberam um pouco. Em vez Osvaldo só escreve pra fazer literatura não fala nada não conta nada, só a gente fica meio percebendo que vocês foram felizes lá pelos orientes perfumados. São mesmo perfumados? ${ }^{27}$

Nesse ano, Tarsila e Oswald se casam, a 30 de outubro, e Mário lhes envia os cumprimentos em tom solene:

Permita-me a excelentíssima amiga e correligionária nas lides intelectuais do espírito que lhe venha ofertar bem como ao seu respeitoso esposo, estas florinhas singelas rociadas pela minha amaviosa saudade, que são como a recordação fraudulenta da nossa amicícia fundamentalizada na mútua estima de sentimento que ambos nós três nos correspondemos em perfeito afeto e remembrança dos tempos de antanho. ${ }^{48}$

Terra Roxa e outras terras. São Paulo, jan.-set. 1926. Edição fac-similar. São Paulo: Martins/Secretaria da Cultura, Ciência e Tecnologia, 1977. Em carta a Drummond, de 18 de fevereiro (Carlos \& Mário - Correspondência. Ed. cit., p. 194), Mário comenta o episódio, bem como em cartas a Bandeira, datadas de 21 de fevereiro e 3 de maio (Correspondência Mário de Andrade \& Manuel Bandeira. Ed. cit., p. 274-5; 288-292). Nesta última, reavalia e explica a defesa que fez do livro O homem e a morte, a qual desencadeou o desentendimento na redação de Klaxon em 1922, referido anteriormente.

47 Correspondência Mário de Andrade \& Tarsila do Amaral. Ed. cit., p. 95-100.

48 Idem, p. 100. 
Não há no arquivo de Mário cartas remetidas por Oswald ou Tarsila em 1927, quando o casal esteve a maior parte do tempo no Brasil. Ao publicar Amar verbo intransitivo, o autor presenteia-os com um exemplar, com a seguinte dedicatória: "Pra/ Tarsivaldo/ constante sempre serei/ Mário de Andrade/ S. Paulo/ janeiro 927",49 Pouco depois, a 24 de março, Oswald publica no Jornal do Commercio, em sua coluna Feira das Quintas, $o$ artigo "Álvaro Moreyra e outras questões que não são para todos" 5o Aí faz duras críticas ao livro, considerando-o "passadista", "um livro parecidinho com a vida", que seria um grande livro "se estivéssemos ainda no tempo da contribuição documental", e culmina debochando do escritor: "Um Max Jacob do Bairro do Limão. Apenas Max Jacob é fotogênico, Mário não é. Não serve nem para Carlito nem para Rodolfo Valentino". Segundo alguns críticos, ${ }^{51}$ Mário reage ao artigo com o poema "Ponteando sobre o amigo ruim", datado de março de 1927 e publicado em Remate de Males.52 Porém, em carta a Pedro Nava, de 10 de maio, ${ }^{53}$ conta que pediu a Oswald que provasse as acusações apresentadas no artigo, ele "embatucou", mas "isso não tem importância, continuamos amicíssimos". Prova disso é que, a 10 de agosto, o casal Tarsiwaldo, regressando de viagem à Europa, surpreende Mário e o grupo que o acompanha na viagem ao Amazonas, em escala no porto da Bahia, ${ }^{54} \mathrm{e} \mathrm{em} \mathrm{dezembro,} \mathrm{assinam} \mathrm{juntos} \mathrm{o} \mathrm{poema} \mathrm{"Homenagem}$ aos homens que agem", publicado no número 4 da revista Verde, de Cataguases: "Poema de Marioswald (do livro inédito Oswaldário dos Andrades)" 55

49 Reproduzida em AMARAL، Aracy A. Tarsila: sua obra e seu tempo. São Paulo: Edusp/Perspectiva, 1975, vol. 1, p. 399. 50 ANDRADE, Oswald de. Telefonema. Vera Chalmers (Org.). $2^{\mathrm{a}}$ ed. Rio de Janeiro: Civilização Brasileira, 1976, p. $39-43$. 51 Cf. BOAVENTURA, Maria Eugenia. Op. cit., p. 141، e Carlos \& Mário - Correspondência. Ed. cit., nota 63, p. 297.

52 Poesias completas. Op. cit., p. 259-60. Cabe lembrar que Mário, em 19 de março de 1944, confidenciava a Mário da Silva Brito: "Ronald de Carvalho [...] uma feita, depois duma carta minha cheia de censuras a um livro dele, me falou que a amizade era um jogo de mútuas condescendências. Naquele tempo eu tinha a inflexibilidade da força do homem comigo, me recuei, as nossas relações esfriaram pra sempre e dele me nasceu o poema 'Ponteando sobre o Amigo Ruim”'. (BRITO, Mário da Silva. Diário intemporal. Rio de Janeiro: Civilização Brasileira, 1970, p. 177). Agradeço esta informação a Marcos Antonio de Moraes.

53 Correspondente contumaz: cartas a Pedro Nava, 1925-1944. Fernando da Rocha Peres (Org.) Rio de Janeiro: Nova Fronteira, 1982, p. 87-91.

54 Cf. FONSECA, Maria Augusta. Op. cit., p. 164.

55 Verde. Revista Mensal de Arte e Cultura: Cataguases, ano 1, n. 4, p. 9, dez. 1927. Edição fac-similar. São Paulo: Metal Leve, 1978

182 - ANDRADE, Gênese. Amizade em mosaico... 
Quando Oswald completa 38 anos, no dia 11 de janeiro de 1928, recebe de presente de Tarsila uma tela que lhe causa grande surpresa. Junto com Raul Bopp, batizamna Abaporu ("que come gente", em língua tupi) e decidem fundar um movimento aí inspirado. Assim se inicia a Antropofagia, cujo manifesto é publicado no primeiro número da Revista de Antropofagia, de maio desse ano.

$\mathrm{Na}$ fase inicial do movimento antropófago e até a primeira dentição da revista, Tarsila, Oswald e Mário ainda são bastante próximos, embora haja provocações, desentendimentos e desacordos cada vez mais frequentes. Macunaíma, também publicado nesse ano - que teve um trecho antecipado no segundo número da revista, em junho, antes de chegar às livrarias -, é reivindicado como uma manifestação do movimento, e alguns críticos apontam nesse herói traços oswaldianos. ${ }^{56}$ Data de 19 de maio de 1928 a última carta de Oswald que integra o arquivo de Mário:

Você nem sabe como escreveu uma coisa linda. Linda e profunda. ${ }^{57}$ Quando eu chegar (tempestadinha d'homem) faço questão que você me raconte as maravilhas de Marajó. E eu te levarei as gravatas de Paris. Topa!

Tudo bem

A antropofagia é um fato.

Escrita a bordo do Alcântara, quando Oswald viajava a Paris com Tarsila, que lá realizaria sua segunda exposição individual, é a carta mais carinhosa dirigida ao amigo e, como a primeira correspondência, uma das poucas sem piadas. Mário responde ao casal no mesmo tom, a 16 de junho:

56 Cf. CANDIDO, Antonio. Digressão sentimental sobre Oswald de Andrade. In: Op. cit., p. 78.

57 Refere-se ao poema "Manhã" (cujo último verso parodia no trecho que destacamos na carta), publicado no número 1 da Revista de Antropofogia: "[...] Tinha um sossego tão antigo no jardim,/ Uma fresca tão de mão lavada com limão/ Era tão marupiara e descansante/ Que desejei... Mulher não desejei não, desejei.../ Se eu tivesse a meu lado ali passeando/ Suponhamos, Lenine, Carlos Prestes, Gandhi, um desses!...// Na doçura da manhā quase acabada/ Eu Ihes falava cordialmente: - Se abanquem um bocadinho/ $E$ havia de contar pra eles os nomes dos nossos peixes/ Ou descrevia Ouro Preto, a entrada de Vitória, Marajó,/ Coisa assim que pusesse um disfarce de festa/ No pensamento dessas tempestades de homens". Ao ser recolhido em Remate de males, livro publicado em 1930, o poema traz, em seguida ao título, a data entre parênteses: "18-III-1928". Cf. ANDRADE, Mário de. Poesias completas. Op. cit., p. 267. 
escrevo-vos primeiramente para saber da vossa saúde o que muito me contenta. [...] Quanto a mim vou passando como Deus quer e são boas as minhas disposições tanto fisiológicas como mentais. E vós, amigos meus, como ides? onde estais? etc. Aceitai um puro abraço deste amigo que muito vos quer. Ride! Ride e aproveitai a mocidade porque isso, além de ser natural e consoante às leis da natura, me enche de puro gozo amigal. ${ }^{58}$

As últimas cartas, assim como algumas dedicatórias citadas, espelham uma grande amizade caracterizada pela admiração mútua, quase sempre, no caso de Oswald, encoberta pelo caráter intempestivo, mordaz, e pelo prazer da blague e do riso solto.

Cacos de sentimento Em meados de $1929,{ }^{59}$ quase um ano depois da última carta de Oswald, Mário rompe definitivamente com ele, por motivos até hoje não totalmente esclarecidos. Especula-se que as razões principais foram a disputa pela liderança do movimento modernista e questões políticas. Não são descartadas, porém, as atitudes mordazes de Oswald e suas impiedosas blagues. Mário da Silva Brito, em depoimento registrado no documentário Miramar de Andrade, afirma que a causa da briga foi uma referência que ele fez ao amigo como "boneca de piche".60 Segundo Aracy Amaral, os motivos do rompimento foram os constantes ataques de que Mário foi alvo na segunda dentição da Revista de Antropofagia, desencadeados por uma atitude sua reprovada pelos companheiros: ter comparecido a uma reunião em que estava presente Alberto de Oliveira, na casa de Yan de Almeida Prado. ${ }^{61}$ No texto "Os três sargentos", de 14 de abril de 1929, assinado por Cabo Machado (provável pseudônimo de Oswald, que remete ao poema homônimo publicado em Losango

58 Correspondência Mário de Andrade \& Tarsila do Amaral. Ed. cit., p. 101.

59 Em carta a Mário, de 6 de maio, Bandeira conta-Ihe: "Alcântara informou-me que você, Paulo Prado, etc. e Guilherme romperam com Miramar". A resposta de Mário a essa carta, de 11 de maio, tem um longo trecho suprimido ao ser publicada, que provavelmente tratava desse assunto. Correspondência Mário de Andrade \& Manuel Bandeira. Op. cit., p. 415-416.

60 Miramar de Andrade. Roteiro e direção: Cristina Fonseca. São Paulo: TV Cultura, [1990?].

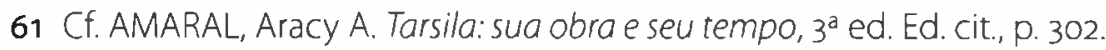


cáqui ${ }^{62}$ ), o autor de Macunaíma é caracterizado como "o nosso Miss São Paulo traduzido em masculino", e aí se insinua que sua amizade com os escritores do grupo Verde motiva a realização de críticas parciais, não isentas. ${ }^{63} \mathrm{O}$ assunto é retomado em "Moquém", de 24 de abril, assinado por Tamandaré (pseudônimo de Osvaldo Costa), com mais duros ataques, acusando-o de fazer uma crítica de "comadrismo indecente". "Miss Macunaíma", publicado em 26 de junho, assinado por Otacílio Alecrym ${ }^{64}$ (que não pudemos identificar), é uma paródia que pode ter interpretações diversas e remete ao texto "Miss Brasil", publicado na coluna Táxi, no Diário Nacional de São Paulo, a 20 de abril. ${ }^{65}$ Pairam sobre isso tudo insinuações sobre o homossexualismo de Mário, questão ainda a ser discutida pelos críticos do Modernismo.

Em carta dirigida a Tarsila, para ser lida também por Oswald, a 4 de julho, Mário fala do rompimento com o amigo, referindo-se provavelmente a esses fatos. Visivelmente abalado, lamenta o ocorrido:

Por isso mesmo que a elevação de amizade sempre existida entre você, Osvaldo, Dulce e eu foi das mais nobres e tenho a certeza que das mais limpas, tudo ficou embaçado pra nunca mais. É coisa que não se endireita, desgraçadamente pra mim.

[...] E quanto a mim, Tarsila, esses assuntos, criados por quem quer que seja (essas pessoas não me interessam), como será possível imaginar que não me tenham ferido crudelissimamente? Asseguro a vocês [...] que as acusações, insultos, caçoadas feitos a mim não me podem interessar. Já os sofri todos mais vezes e sempre passando bem. E nem uma existência como a que eu levo pode se libertar deles. [...]

62 ANDRADE, Mário de. Poesias completas. Ed. cit., p. 144.

63 Nesse texto, também é atacado Antônio de Alcântara Machado, que havia dirigido a primeira dentiçāo da Revista de Antropofagia, mas fora afastado na segunda fase e havia rompido com Oswald. O autor de Pathé-baby apresenta sua versāo dos fatos, afirmando também que o rompimento de Mário com Oswald fora motivado por esses textos, na correspondência a Alceu Amoroso Lima, datada de 15 de maio de 1930; recolhida em BARBOSA, Francisco de Assis. Intelectuais na encruzilhada: correspondência de Alceu Amoroso Lima e Antônio de Alcântara Machado (1927-1933). Rio de Janeiro: Academia Brasileira de Letras, 2001, p. 82-5. Nesse ano de 1929, Tarsila, traída por Oswald com Pagu, separa-se dele, e Paulo Prado, alvo de ataques na mesma revista, também rompe com o antropófago.

64 Revista de Antropofagia (1ª e $2^{\mathrm{a}}$ dentições. 1928-1929). Edição fac-similar. São Paulo: Metal Leve, 1976.

65 ANDRADE, Mário de. Táxi e crônicas no Diário Nacional. Telê Porto Ancona Lopez (Org.). São Paulo: Livraria Duas Cidades/ Secretaria da Cultura, Ciência e Tecnologia, 1976, p. 89-91. 
Mas não posso ignorar que tudo foi feito na assistência dum amigo meu. Isso é que me quebra cruelmente, Tarsila, e apesar de meu orgulho enorme, não tenho força no momento que me evite de confessar que ando arrasado de experiência. ${ }^{66}$

Conclui evidenciando seu desejo de preservar a amizade com Tarsila, a quem se dirige muito grave e respeitosamente, o que de fato ocorreu, como o comprova a correspondência que mantiveram até 1940 .

Alguns depoimentos de pessoas próximas a Oswald ${ }^{67}$ informam que, após várias tentativas frustradas de reconciliação, este passou a intensificar seus ataques a Mário. Por outro lado, em outras cartas, anteriores e posteriores ao rompimento, este último varia a expressão de seus sentimentos com relação ao antropófago. A análise desses fatos, contudo, seria tema para outro artigo. Segundo Candido, por não guardar rancor e esquecer facilmente as birras, era natural que Oswald quisesse reconciliar-se; porém, o motivo alegado por Mário para não fazê-lo, embora já tivesse rompido e feito as pazes com outras pessoas, é que o continuava respeitando. ${ }^{68}$

Em carta a Bandeira, datada de 18 de janeiro de 1933, Mário refere-se ao ex-amigo nos seguintes termos:

eu odeio friamente, organizadamente, a quem certamente não ofereceria um pau à mão, pra que ele se salvasse de afogar. Você está vendo que sou assassino em espírito! Mas é que eu me gastei excessivamente com ele. Fomos demasiadamente amigos para que eu possa detestá-lo pelo que ele me fez. Mais o detesto pelo que ele não fez, [...]

66 Correspondência Mário de Andrade \& Tarsila do Amaral. Ed. cit., p. 106. Em depoimento a Léo Gilson Ribeiro, em 1972, Tarsila dá a entender que esta seria uma resposta de Mário a uma carta sua, enviada a pedido de Oswald, propondo que fizessem as pazes (Apud Carlos \& Mário - Correspondência. Op. cit., p. 437, nota 10). Porém, não há informaçōes sobre essa carta, pois a única correspondência de 1929 entre Tarsila e Mário, recolhida por Aracy Amaral, é esta de 4 de julho.

67 Tarsila, no depoimento a Léo Gilson Ribeiro, citado, afirma: "[...] quando o Oswald viu que ele não voltava mesmo às boas, continuou a falar mal do Mário". (Apud Carlos \& Mário - Correspondência. Op. cit., p. 437, nota 10). Antonio Candido registra: "Contava-se que Oswald fazia sobre o antigo amigo piadas terriveis e divertidas, que corriam mundo. Mas eu só o ouvi falar dele no plano intelectual, com discrição e naturalidade, talvez porque o tempo da virulência tivesse passado quando estreitamos relaçōes". Em "Digressão sentimental sobre Oswald de Andrade". In: Op. cit., p. 79.

68 Cf. "Digressão sentimental sobre Oswald de Andrade". Op. cit., p. 76 e 79. 
e se eu não salvava o Osvaldo se se desse a ocasião disso, não seria por ódio propriamente, seria por despeito. ${ }^{69}$

Mais de um ano depois, em carta a Drummond, de 16 de dezembro de 1934, é mais explícito quanto a seus sentimentos:

[...] pensei longamente no Osvaldo de Andrade. Está aí um com o qual eu jamais farei as pazes enquanto estiver na posse das minhas forças de homem. Não é possível. Há razões pra odiar, e talvez eu tenha odiado mesmo no princípio. Mas foi impossível, percebi isso muito cedo, perseverar no ódio. É besteira isso de falar que o ódio é uma espécie de amor, não é não. Como tinha de recontinuar no amor tive de abandonar o ódio. [...] o que hei de fazer, não faço pazes, não sei se existe etc., mas a verdade é que eu quero bem ele. ${ }^{70}$

Porém, se a reaproximação fracassou, como protagonistas do Modernismo, mesmo depois do período heróico, jamais se afastaram. A admiração e a disputa, que caracterizaram a amizade, permaneceram após o rompimento. Em 1942, Mário faz um balanço da Semana de 22 em conferência no Rio de Janeiro e em São Paulo, ${ }^{71}$ e não deixa de mencionar Oswald entusiasticamente: "a figura mais característica e dinâmica do movimento". Em 1944, quando a caravana modernista que acompanhou Blaise Cendrars ao Rio de Janeiro e às cidades históricas de Minas Gerais completa vinte anos, é a vez de Oswald rememorar, na conferência realizada em Belo Horizonte, sem omitir o nome de Mário. ${ }^{72}$ Em carta a Bandeira, de 20 de janeiro do mesmo ano, Mário admite continuar lendo a obra do então inimigo ${ }^{73} \mathrm{e}$

69 Correspondência Mário de Andrade \& Manuel Bandeira. Op. cit., p. 547-8.

70 Carlos \& Mário - Correspondência. Op. cit., p. 435-6. Sobre o assunto, v. tb., neste número de Teresa, a carta de Mário de Andrade a Fernando Mendes de Almeida, em 25 set. 1940 ("Documentos").

71 ANDRADE, Mário de. O movimento modernista. In: Op. cit., p. 253-80.

72 ANDRADE, Oswald de. O caminho percorrido. In: Ponta de lança. São Paulo: Globo, 2004, p. 162-175.

73 Ao contrário do que se poderia supor, ingressaram, na biblioteca de Mário, obras de Oswald publicadas depois do rompimento:

- Marco zero I. A revolução melancólica, de 1943, traz dedicatória de Oswald de Andrade Filho;

- Marco zero ll. Chão, de 1945, é dedicado pelo próprio Oswald, durante o Primeiro Congresso Brasileiro de Escritores - realizado em São Paulo, de 22 a 27 de janeiro -, mas suas folhas nāo chegaram a ser cortadas. A dedicatória é a seguinte: "Exemplar do congressista/ Mário de Andrade/ p.e.o. de/ Luiz Jardim/ o/ Oswald 
reconhece seu valor: "Se eu fosse crítico literário, agora, eu seria obrigado a aprovar calorosamente uma obra como Marco zero pelo que representa, mas cujo autor é um crápula completo"74

Vista a posteriori, a primeira correspondência de Oswald adquire um valor simbólico, pois prenuncia o luto que terá de guardar pela morte de Mário, a qual precede a sua em quase dez anos, amargando a frustração por não terem refeito a amizade. Estando em uma estação de águas, ao tomar conhecimento pelos jornais do fato ocorrido em 25 de fevereiro de 1945, só lhe resta o choro convulsivo. A frase lapidar de Antonio Arnoni Prado sintetiza o verdadeiro destino de Mário e Oswald: "separados na vida, mas sempre próximos na ambiguidade dos sonhos e no poder alusivo da literatura". ${ }^{5}$

Gênese Andrade é pesquisadora, doutora em Letras pela Universidade de São Paulo e atualmente realiza o pós-doutorado na Unicamp, organizadora de Feira das Sextas [Globo, 2004] e Un diálogo americano: modernismo brasileño y vanguardia uruguaya (1924-1932) [com Pablo Rocca; Universidad de Alicante, 2006].

de Andrade/ 1945 - Jan". A sigla "p.e.o." significa "por especial obséquio". Em carta a Drummond, de 11 de fevereiro de 1945, Mário faz comentários sobre o Congresso, mas não menciona o nome de Oswald. Em Digressão sentimental sobre Oswald de Andrade. In: Op. cit., p. 79-80, Candido conta sobre a participação de Mário e Oswald no Congresso, no qual o crítico também esteve presente;

- de Poesias reunidas O. Andrade, também de janeiro de 1945, embora sem dedicatória, chegou à rua Lopes Chaves nada menos do que o exemplar "A", o primeiro dos vinte especiais, em papel creme, com uma ponta-seca original de Tarsila, como informa o cólofon.

Na biblioteca de Oswald, há apenas, das obras de Mário desse período, Poesias, publicado em 1941, com dedicatória de Oswald para sua esposa Maria Antonieta d'Alkmin, datada de 1943. Este exemplar integra o Fundo Oswald de Andrade, do Cedae, IEL-Unicamp. Porém, como seus pertences se dispersaram, pode ser que outros livros de Mário posteriores ao rompimento tenham passado por suas mãos, muito provavelmente sem dedicatória do autor.

74 Correspondência Mário de Andrade \& Manuel Bandeira. Op. cit., p. 670

75 PRADO, Antonio Arnoni. "Antonio Candido, anotador à margem." In: Trincheira, palco eletras. São Paulo: Cosac Naify, 2004, p. 310-1. A esse ensaio (p. 309) pertence também o trecho que constitui a epígrafe deste artigo. 